\title{
ESTUDO COMPARATIVO DA INCIDÊNCIA DE INSUFICIÊNCIA CARDÍACA - EM TEMPOS DE COVID-19 E NO MESMO PERÍODO DO ANO EM 2019
}

\author{
COMPARATIVE STUDY OF THE INCIDENCE OF HEART INSUFFICIENCY - \\ IN COVID-19 TIMES AND IN THE SAME PERIOD OF THE YEAR 2019
}

Letícia Santos Trad*, Luana Hantequestt De Lima, João Pedro Zuin Do Amaral.

UNINGÁ - Centro Universitário Ingá, Maringá, PR, Brasil.

*leticiastrad@gmail.com

\section{RESUMO}

A COVID -19 é uma doença viral desencadeada pelo novo coronavírus (SARSCoV-2). A doença leva a um quadro respiratório o qual tem início com sintomas gripais leves que podem evoluir até uma síndrome do desconforto respiratório agudo, consideravelmente fatal. $12 \%$ dos afetados pela doença viral desenvolvem uma lesão cardíaca aguda que está associada a piores resultados evolutivos, especialmente nos casos de pacientes com doenças cardiovasculares prévias. Apesar de o sistema cardiovascular não ser o principal alvo do SARS-CoV-2, ele pode ser prejudicado de diversas formas, dentre elas podemos citar: alteração na regulação neuro-humoral através lesão miocárdica direta; tempestade de citocinas decorrentes da inflamação sistêmica crônica, resultando em lesão e falência cardíaca; aumento da demanda cardiovascular associada à hipóxia, podendo evoluir para lesão miocárdica aguda; desestabilização das placas coronarianas devido ao efeito pró-trombótico e inflamação sistêmica, sendo capazes de causar infarto agudo do miocárdio; uso de medicamentos que são danosos ao sistema cardiovascular; além de distúrbios hidroeletrolíticos, levando à arritmias. Este trabalho objetivou avaliar a prevalência da insuficiência cardíaca durante o período da pandemia do COVID19 na região do Paraná, do mês de março até agosto de 2020. O referente estudo trata-se de uma pesquisa epidemiológica na qual a fonte de dados utilizada foi o registro do Departamento de Informática do Sistema Único de Saúde (DATASUS). Os dados obtidos para o estudo foram: óbitos, internações no período e variáveis demográficas (sexo). Durante o período de pandemia do COVID-19, entre maio até agosto de 2020 no estado do Paraná, foram registrados 818 óbitos por insuficiência cardíaca, sendo que o total de óbitos no mesmo período e região no ano de 2019 foram de 877 casos. Agora, em relação aos meses isolados de pandemia, durante o pico dos casos (maio de 2020) observamos aumento de 1 caso de óbito em relação ao ano anterior. Além disso, observa-se que, no mesmo período analisado em 2020, o número de internações por insuficiência cardíaca foram aproximadamente $37 \%$ menores que no ano anterior. Neste estudo, o sexo masculino teve prevalência no número de mortes em ambos os períodos analisados. O estudo evidenciou que, apesar da relação entre mortalidade de COVID-19 com doenças cardíacas subjacentes, como no caso a insuficiência cardíaca, os números de óbitos totais de pacientes com essa doença crônica não aumentaram no período de pandemia em comparação com o mesmo período no ano anterior. Esses dados podem refletir uma melhor 
preparação dos médicos, hospitais e áreas de saúde em atender pacientes em estado grave devido a pandemia, algo que refletiu positivamente no estado de saúde das pessoas portadoras dessa doença crônica.

Palavras-chaves: Atestado de óbito. Coronavirus. Infecções por Coronavirus. Insuficiência cardíaca. Pandemias. 